\section{Processes controlling the composition of clastic sediments}

\author{
(papers from the GSA annual \\ meeting, 1991)
}

\section{Edited by Mark I Johnsson and Abhijit Basu}

\section{Geological Sociely of America, Special Paper 284, 1994. 352 pp.. paperback. US\$75.00, JSBN 0813722845}

This latge lormat book, about an inch thick. containins 20 papers presented at the annual GSA meeting in 1991 . It is headed by an impressive list of auspicious aluthors so I opened it with great expectations.

Books on provenance are fiew and far between. Gian Zeilfas (1985) landmark compilation 'Provenance of Arenites" and Andy Montons" (1991) comparable 'Developments in Sedimentary Provenance Studies are the only recent texts. and other than Marial Manges (1992) Atlas of Heary Minerals: the dedicated provenancist (should there he such a term) has recourse 10 either a few seminal papers or to the wellknown texts from the golden era of sedimentary provenance studies. Given the recent upturn in interest of sediment detrital composition-driven largely by the oil geologists aned for high resolution correlation in otherwise uncorrelatable reservoir rocks -almost any book that addresses aspects of sediment composition is welcome.

Mark Johnsson and Abhijit Basu have tried o bring together an integrated, process approach to understanding the composition of elastic sediments (the editors view of what the book is about, is given on page vii). The book contains two introductory chapters followed by the main body of the book that addresses what are perceived to be the main controls on the composition of clastic sediments - souree rock and teetonics (for some reason linked together): chemical weathering: mechanical processes, and various aspects of processes that operate on provenance within the depositional basin. The final three chapters discuss the influence of sediment rates and fluxes on provenance. culminating with a bold attempt to provide a quantitative determination of the rate of erosion of source materials based on sediment composition.

I am not entirely convinced that the book accomplishes what it ambitiously set out $10 \mathrm{do}$. Despite the proclaimed process approach, $60 \%$ of the papers revert to a case history format. These are full of marvellous detail. but many of the case histories described appear to be just examples of yet more-albeit well documented-spe- cial cases. It is particularly difficult 10 draw generally applicable conclusions from these chapters, aldhough most of them are well presented and some, thought-prowoking. Perhaps I expect too much. It may be that the subject of sediment provenance does not lend itself readily to a truly integrated. process-orientated analyticial approach. Even if it does, the subject may not have matured to the level where such an approach is appropriate. However, (1) my mind, sediment provenance shouldn't be such a great intellectual challenge. The parameters that influence and modily clats tic sediment composition are well known (and ably summarised by Johnsson in Chapter 1). Establishing a qualitative understanding of sediment provenathe should be straightforward, and making this quantitative not that far behind.

Disappointingly, not all the contributing authors seem to have grasped this and many fail to take on board all the issues that Johnsson addresses in his introduction. The most obvious omission-- throughout the book-is the almost complete absence of consideration of diagenetic eflects on sediment composition, despite the commendable appearance of papers that use geochemical techniques and isotopes to constrain provenance (Chapters 2.6 and 7 ). It is perhatps unfortunate that my interest lies in diagenesis, because this omission spoils the book for me. Given the subject of the hook ('Processes controlling the composition of clastic sediments", remem ber) post-depositional (diagenetic) effects on sediment composition receive only brief mention in the introductory chapters and mere passing mention in the preamble within a few subsequent papers. There is nol one paper that systematically addresses the influence that diagenesis can exert in dramatically modifying the original detrital composition of elastic sediments. I lind this remarkable given that Pettijohn (1957) was one of the first sedinentary petrographers 10 recognise the importance of selective dissolution of the more unstable detrital minerals in modirying sediment composition and even coined the term intrastratal solution (although he actually meant dissolution) to account for so-called mature heavy mineral assemblages in ancient sandstones. The importance of this process is reflected in papers such as that of Harris (1979) who describes the generation of at quarts arenite from an arkose simply by the diagenetic removal of detrital feldspar. Add to this the extensive chemical alteration of sandstones brought about by replacement reactions (such as albitisation; Ramseyer and others. 1992), the formation of red beds from immature lirst cycle arkoses dur ing early diagenesis (Walker. 1976) and the gray wacke diagenetic matrix story (Whetten and Hawkins, 1970), then the importance of diagenetic effects on the composition of clastic sediments is at least as great as any of the other parameters the book concentrates on

Of the remaining $40 \%$ of papers in the book that do not revert to the case history formal. one is theoretical. two are experimental and only five can be considered process-orientated. Although it is probably grosisly unfair to single out individual papers for special mention. I choose to do so. To my mind, the papers by Heins (Chapter 8 ) and Palomeres and Arribas (Chapter 19) have the potential to make important, original contributions to the subject. Heins identifies source rock texture ans an important but largely overtooked influence on sandstone composition. Palomeres and Arribas show that source rochis of eontrasting lithologies hatwe very different potentials to generate detritus, and that unless the "sand generation inclex is considered. traditional yuartzfoldspar-rock trayment plots of sediment composition reflece little of the variation of the source areal lerrain. It is the methodological approach adopted in these papers 10 provide principles from modern depositional systems which can then be applied to ancient geological systems- that is likely to break new ground.

Overall, given the difficulties in putting together a compilation volume from a conference gathering, this book is an excellent achievement. It is bursting with information, including considerable amounts of tabulated orginal data. It is not the sort of book most sedimentary petrographers will rush to buy beciuse it is $100 \mathrm{spe}-$ cialised, but ats a collection of related papers on sediment provenance, it certainly ranks alongside Zuffa (1985) and Morton (1991) and will be a useful reference text.

\section{References}

Harris. N B. 1989, Diagenelic quats arenite and the destruction of secondary porosity: an example from the Middle Jurassic Brent Sand sonc of northwest Eamop: Geology. v. 17. pp. $361-364$

Mange, M, 1902, Alas of heavy mincrals: Chapmanl and llall, $1.5 \mathrm{pp}$.

Mortor. A. 1991, Developments in sedimentary provenance studies: Spectal Publication Gerlogical Soxicty of london. 060. 57.

Penjohn. J J 1957. Sedimentary rocks: Harper and Brothers. New York, 718pp.

Ramseyer, K. I ichener. P C. and Boles, J R. 1988. Mechanism of plagioclase albitisation: Joumal of Sedimentary Petrology, v. 62, pp. $3+9-350$

Waller, I R 1976, Diagenetic origin ol continental red beds in talke. H, ed., The continental Permian in central, west and south Europe. NATO ASI Series C. no. 22, pp. $240-282$.

Whetten. I T, and Hawkins, J W, 1970, Diagenetic origin of gray wache matrix minerals: Sedimencology v. 15. pp. 347-301.

Zulfa, G G jox5. Provenance of amenites. NATO ASI Proceedings. Dordrecht. D) Reidel.

\section{SD Burley,}

The University of Manchester. UK 


\section{Geology of Western Himalaya}

\section{Vikram C Thakur}

Pergamon Press Physics and Chemistry of the Earth, Volume 19, Parts I-VI. 1993. $36.3 \mathrm{pp}$.. hardback, UK£345.00. ISBN 0080422063

The youngest. the highest and the most beuutiful Himalayan mountain belt has attracted many of the world's geoscientists because of its uniqueness, and it has become a laboratory in which numerous geodynamic processes may be investigated. Such greal interest requires proper coteratge with respeet to publication and nomenclature. Vikiam Thakur's book the Cieology of Western Himalava is an excellent altempt. It covers the Himalaya between Pakistan and Nepal and provides vivid descriptions of the various tectonic units in a most comprehensive and elaborative manner. The author. Director of the Wadia Institute of Himalayan Geology in Dehradun. India. has drawn upon his 20 years of valst experience in the belt and has brought logether and summarised most of the information from geological maps published so far by investigators from India. Pakistan and elsewhere in one handy volume, including his own observations and thoughts. This book updates our knowledge on structure, petrology, geochemistry, sedimentology. hiostratigraphy and geochronology up to 1992. Most of the tectonic zones have been geographically traed across national and provincial boundaries unlike Gansser's classical book (ieofogy of the Himalaya published in 1094. wherein the treatment is essentially geo graphical.

The introductory chapter provides a general background including physiouraphy and drainage, and gives an insight into the tectonic setting with respect to the Indian Peninsula and the Tibetan Platealu. Along with this a geological map of the Westem Himalaya has also been compiled. at a scale of 1:1000000, showing tive main traceable tectonic zones. The next tive chapters elaborate on the geology of different tectonic zones and also incorporate details of other characters. The last chapter discusses the interactions of different geological processes, which have resulted in the presentday Himalaya. This chapter provides an insight of Proterozoic sedimentation on the crystalline basement and of the superposed geodynamic processes during the

Himalayan orogenesis.

Chapter 2 also incorporates recent magnetostratigraphical datla from the SuhHimalayan zone, besides presenting detill of the geological setting and faunal record. Thatkur s idea to incorporate the Gatanga Basin into the Outer Himalaya zone may not find many supporters in view of the lat -
Ier's distinct physiographic and geological characteristics.

Thakur's attempts to build a composito stratigraphic column of the essentially Pro terozoic Lesser Himalayan sedimentary secuence is rather successful. even though the stratigraphic relationships are lectonically imbricated and have created numerous viewpoints. Unfortunately the famous marine Permian fauna around Duggadda/Lansdown beneath the metamorphic nappe do not find a place in Thak ur"s stratigraphic scheme (Figure 3.16).

The Higher Himalayan Zone is eloquently described through numerous wellstudied regions in Chapter 4 , which provides a good insight into this vital collision belt. where a Proterozoic basement was remobilised during the Himalayan orogeny. However. certain confusion still persist in description. e.g. in the Sutlej valley section. While identifying the Wangtu gneissic com plex as having $2025 \pm 85 \mathrm{Ma}$ old gncissic components in the text. Thakur classifies these as members of the Jutogh Group on the map and cross-section (Figure 4.9). I ikewise the Chail and Jutogh groups are not differentiated in the extreme west of the map in spite of detailed mapping done by olher workers.

Unfortunately, the confusion also per sists in the treatment of some of the metamorphic nappes in the Higher Himalayan 7one. e.g. the Jutogh Group. This important unit is also incorporated in the Lesser Himalayan Zone (p. 8()). In my opinion, the time is now ripe to discard the use of classical terminology and adopt a more realistic scheme, based upon the gross lithological, statigraphic and tectonic characters.

Chapters on the Tethys and TransHimalayan zones are most elaborate and provide an excellent picture of a very complex geodynamic history. in which the passive Tethyan margin has been deformed into a mountain range through subduction related processes. Contradictions prevail even here, with a cross-section (Fig. 7.2) through the Trans-Himalaya showing the I aldakl Batholith sitting over the Karakoram basement crust. This interpretation indicates crustally derived melts for the Ladakh Batholith inconsistent with its Andean-type setting and calc-alkaline affinity (pp. $237-$ 238. 202).

Apart from its exhorbitant price tag. which may discourage even libraries from acquiring it, this book is a convenient source for the Himalayan earth-scientist. It will be popular and particularly uselul for those who do not have casy access to the many publications in the Indian journals. The author has made a very signilicant contribution to Himalayan geology.

\section{A K Jain}

University of Roorkee India

\section{Uttarkashi earthquake: October 201991}

\section{P Vohra and D Gupta Sarma}

Geological Survey of India Special

Publication 30. 1992. 217 pp.,

hardback, Rs 165.00 ; UKE20.00);

US\$60.00

The International Decade for Natural Disaster Reduction, of which we are now approaching the mid-point, is providing a context in which to examine the problem of destructive earthquakes. No other type of natural disaster kills so many people so quickly: while famine may be responsible for more deaths overall, this is over a period of years. A major earthquake may kill 200000 people in al matter of seconds. For many years, earth scientists have looked to carthquake prediction schemes as providing the best waly to prevent future disasters from earthquakes. But after 30 years of intensive research, we are still no nearer al reliable means of earthquake prediction. and it is increasingly clear that other means of protection from earthquakes need to be adopted in order to reduce the death toll in luture events.

This means examining past earthquakes and analysing how and why so much destruction was caused, to enable protective measures to be adopted in future. This is illustrated well in the recent extensive sludy prepared and published by the Geological Survey of India of the 20 October 1991 Utrarkashi earthquake. which oceurred in the Ciarwhal Himalaya district of Northern India. This earthquake had a magnitude of 6.6: 72.3 people were killed, thousands were injured and 36000 houses were damaged or destroyed in the Uttarkashi district alone.

The 217-page field investigation report of this earthquake gives the results of the survey carried out after the earthquake in considerable detail, with over 100 photographs, many in colour, and many excellent line drawings showing exatcly what the failure modes of the typical housing stock were. The bulk of the report is a district-bydistrict, village-by-village description of the damage. There are some good illustrations of contrast between the performance of relatively well-constructed and relatively poorly constructed buildings in the same village.

Much other information is also provided: background on the geology. past seismicity and seismotectonics: considerable data on the large number of landslides that were generated, a catalogue of the altershocks that were recorded, and interpretation of focal mechanism and ground motion attenuation. The one obvious shortlall is a list of assigned intensities for the various villages - an isoseismal map is plotted. hu not the intensity data on which it is based. 
I also have a few reservations about some sections of the seismological interpretation: it seems rather unfair to pull one published attenuation equation (by Kenneth Campbell. for California) from the literature and make a conclusion out of the fact that the very low acceleration data points from this earthquake don tit fit.

The physical production of the report is. I think, rather high by the standards of many Astan countries, though Western readers may tind the photos rather faded and the printing rather quaint. But overall. this is a valuable publication and I would like to see more like it. It is by collating and studying the effects of past earthquakes in this way that we will learn to protect populations against the earthquakes of the future.

\section{R MW Musson}

British Geological Surves, Edinhurgh, UK

\section{Atlas Tethys palaeoenvironmental maps}

\section{Edited by I Dercourt, L E Ricou and $B$ Vrielvnck.}

Commission for the Geological Map of the World, 1993, 14 maps and 305 pages of explanatory text in English. boxed sel, US\$185 plus postage $\$ 18$ (surface mail); $\$ 20$ (airmail)

Fitty workers have contributed to this impressive publication, sponsored by BP. BRGM, CNRS-INSU, ELF, IFP, IFRE MER, SHELL. TOTAL and UPMC. Of the contributors. 42 are recorded as resident in France, three are from Switzerland. two from Italy, and one each from Austria, Rumania and Ecuador. In addition, in the introduction to the explanatory notes, the editors acknowledge the collaboration of another 74 geologists: relevant contributors are named at the end of each section.

The handy box file contains fourteen coloured palaeoenvironmental maps covering stages of the development of Tethys between the mid Permian (late Murgabian) and the late Miocene (Tortonian stage): a span of 260 million ycars. There is one accompanying volume of explanatory notes, which, after the contents. the two-page list of contributors. and the admirably succinct introduction by the editors, plunges straight into the 15 major sections: which pertain to 14 palaeogeographic maps. The reason for this discrepancy is that the fourth section, by G Stamptli and A Pillevuit, gives an alternative Permo-Triassic reconstruction of Tethyan kinematics to that expounded in the first three sections--an appropriate interpo sition given the greater uncertainties of interpreting the palacogeography of those two periods. There are 48 pages of references at the end.
Although there are 14 maps there are actually 21 printed map sheets in the box take care lest you tear them when extracting and unfolding!): each of the seven maps from the Lower Aptian upwards requires two sheets, a natural consequence of the expansion of the Atlantic and Indian Oceans, so that Australia in the east becomes progressively more distant from the Caribbean in the west. The maps are on rectilinear projection, with an equatorial scale of $1: 200000000$.

The basis for each palaeoenvirommental map was established by LE Rico of the Université Pierre et Marie Curie as part of a set of palinspastic maps for the whole of Tethys. Fifteen palaeoenvironments deduced from lacies, including exposed land and island arc, have been distinguished by different plain colours, nine of these cattegories could be classified as marine. Apart from the three blue categories (marine slope and deep basins) the conspicuous colours on most of the sheets are the yellow (shallow platiorm) and the orange (terrigenous shelf and shallow terrigenous basin. Where appropriate, superimposed patterns in reddish brown. indicate lithology, for which there are 18 categories: also there are special patterns for "submarine hiatus" and 'magmalism?.

Special symbols indicate breccia, reet. oolites, deep sea fans, supply direction, and hydrodynamic features such as upwelling. also surface and bottom currents. Palacolatitudes are shown, present-day coastlines. spreading ridges, subduction indicators and other tectonic features. The symbols for total organic carbon are keyed, in terms of percentage levels, to four organic facies; the organic facies symbols have been used on only three of the maps (Mid-Toarcian, Early Kimmeridgian and Late Cenomanian). DSDP drilling sites and other wells are numbered as appropriale. As a concession 10 other economic interests, there are also symbols for deposits of bauxite, phosphate and gold.

The maps are uncluttered by place names or obscure labels to palacogeographic entities. Hall the legend space is taken up by an alphabetic system (942 combinations of up to four letters), which serves as a key 10 roponymic information

Where subdivisions of stages give their names to the map titles, the lrench version uses inferieur, moven or superieur as appropriate, whereas the English translation uses early middle or late- except for the lower Aptian--an unexplained anomaly.

Each major section in the text is preceded by about half a page of abstract in French: appropriately, English words do not intrude into the French text of the abstracts. However the occasional use of the term seuil instead of the universally understood shelf, in the body of the English text, even in subheadings, would not seem to be justified where some attention to the 'purity' of language is currently regarded as politically correct. Furthermore the typographic and grammatical errors in parts of the English text are somewhat distracting: they could have been remedied by a little more atten tion to final editing. which would have done justice to what must have otherwise been. technically, a Herculean task involving the collation of information from so many experts in their specific tields.

The structure of each report on the 14 stages is fivefold:

$A$ the main characteristics;

B kinemaltics:

C main lithofacies:

D) main palaeoenvironments; and

b main domains.

The kinematics, in terms of plate tectonics, details the plates and blocks accounted for their palacopositions, tectonics of the boundaries, followed by an assessment of accuracy and general comments. The section on the alternative Permo-Triassic reconstruction is not. of course, constrained to that format; it is illustrated by Iwo maps which offer interpretations of the Late Permian (Murgabian) and Late Triassic (Norian), showing the expansion of Neotethys at the expense of Paleotethys. Each of the maps is a "still frame" in the Tethyan epic; their presentation, the annotations and the explanatory notes should be an inspiration to geoscientists. from petroleum geologists to global theo rists, who strive to grasp the entire movie in three dimensions, or simply find out what detail is available on a particular lacies in a given areal. It is acknowledged, for example. that the Alpine Mediterranean scenario is more effectively constratined than are the Indosinian orogenic belts: this is essentially a reference work for which there is no summalry: the reader is left himself to paint the broad picture-should that be his aim.

\section{BD Hackman}

Rhosi-on-Sca, Clusd, UK

\section{Seismic coal exploration, Part B: in-seam seismics}

\section{$L$ Dresen and $H$ Rüter}

Elsevier Science, Handbook of Geophysical Exploration Series, 1994. Hardback, UKt80.0(); US\$130.00, ISBN 0080372260

This is another important book in the Pergamon Series of Handbooks of Geophysical Exploration and is the very tirst to cover the in-seam seismic method, the only geophysical tool that can detect and map minor tectonic faults in front of the coal cutter in deep coal mines. This inexpensive exploration tool enables mining to be planned with a minimum of production losses caused by unexpected geological difficulties. 
The authors, working together for two lecades, have pioneered much of the nethodology in this field, and their book contains everything essential to a thorough Inderstanding of the method and its applicaion. It is a thoroughly scholarly work, with zomprehensive references to earlier work, out is nevertheless very readable. The Idvice of their students was sought on many sspects and, by way of acknowledgement. the students are named as co-authors of the relevant chapters.

After an introductory chapter explaining the motivation for the development of the method, the book begins with a chapter on the physics of channel waves in coal seams, or seam waves. There are two types: the love-type $(\mathrm{SH})$, now named Evison waves, and the Rayleigh type (P-SV). named Krey waves, following Theodore Krey's pioneering work, in the early 1960s. The method relies on the lact that $P$-wave and $S$-wave velocities are lower in coal than in the country rock. The seam waves are essentially interference phenomena between body waves internally reflected at the rool and floor of the coal seam and there are many possible paths tor constructive interference. The waves are therefore very dispersive. A full treatment of this dispersion is given, using the intuitive ray theory description, as well as the rigorous wave theory description. The Love-type wave is always developed in the coal seam and the authors point out that mystery still shrouds the understanding of Love-type (SH) waves generaled by explosive sources.

The third chapter discusses the processing of dispersive channel wave data. introducing the reader to many problems that are not encountered in the processing of conventional seismic reflection data. The processing methods combine lechniques from both earthquake and exploration seismology. although the names are nol always familar: for example. the image construction by lag-sum methods, developed in Britain. is very similar, as the authors point out. to the well-known Kirchholf-Huygens diffraction stack migration of reflection seismology.

Chapter 4 is a very extensive discussion on modelling the behaviour of channel waves in coal seams, using analogue, or scale model laboratory methods, as well as three numerical methods: finjte-difference, finite-element. and the normal-mode summation method. The methods themselves are described quite briefly, but more than 100 pages are devoted to the results of the mod elling, collected from many authors. Modelled effects include: coal seams containing root clays and dirt bands, faults, washouts. and zones of mylonized coal (containing large quanties of explosive gas). The models are analysed systematically. considering both Love and Rayleigh waves, and both transmission and reflection. The modelling is essential for planning the acquisition of the data underground and can determine, for example. which wave type, Love or Rayleigh, should be used to detect the geological disturbances; for Love waves only two-component geophones are necessary, while for the measurement of Rayleigh waves three components must be used.

The underground acquisition of seismic data in coal mines is non-trivial. The danger of explosions is always present and all mines are governed by strict safety regulations that have profound implications for geophysics. Chapter 5 discusses the instrumentation necessary to make the measurements, including the recording system, the seismic source, and the receiver. The first serious approach to develop a safe underground multichannel digital recording system was made in $1975-77$ by Prakla-Seismos, who put a standard Texas Instruments DFS $V$ seismic recording system into specially constructed boxes purged with inert gals. The need for improved portability, a larger number of recording channels, and much higher sample rates to measure the high-frequency waves guided by thin seams. inspired the development by 1985 of an intrinsically safe telemetric recording systen. called SEAMEX, by Westrailische Bergewerkschaftskasse (WBK). A partially flame-proof system known as DAS has also heen developed by BHP for work underground in Australia. The data recorded are only as good as the source and the receiver. For the source, this chapter discusses the merits of various kinds of explosives as well as mechanical sources, which are weaker, but are repeatable and permit stacking. The problem of coupling geophones and accelerometers to coal, which fractures very easily. was solved by WBK, and the very effective pneumatic coupling often gives excellent data. although the authors remark that 'the receiver still remains the weakest link in the in-seam seismic chain".

Chapter 6 discusses the acquisition of the data underground. There are essentially two types of survey: transmission and reflection, although the distinction between the two is often fuzzy, and they are very often used together. Since the chief consideration is 10 image and map struclural features of interest to mining engineers, the layout of the survey is critical, within the constraints imposed by the access, and the spatial and temporal requirements imposed by the processing of the data. Unlike most geophysical surveys, which can often be carried out with only a minimum of supervision and coordination from the client, underground seismic surveys require the close cooperation of the mine management. A very useful section on the practical aspects of carrying out the surveys concludes this chapter

Chapter 7, the final chapter, contains seven published case histories: two from Australia, two from the UK, and three from Germany. The Australian and British surveys essentially established the viability of the tool in those countries and led to its use as a standard tool to aid mine planning. The two British data sets, from Rawdon Colliery and Pye Hill, have great historical significance, as these were used to develop processing methods and have since led to hundreds of British underground surveys. Germany is where the technique was pioneered and by 1970 , long before any British measurements were made, more than 200 surveys had been made in Germany. The three German case histories, all conducted in the late 1980s, show very clearly the quality of the data obtainable with modern equipment. the effect of processing, and the images of faults that may be obtained. Faults with throws of half the seam thickness or less are known from modelling to be difficult to detect, but these may often be carried on the face. Thus the method images exactly those faults that are liable to cause the greatest problems for mining.

The book is very satisfying and a pleasure to read. It comes with an excellent index and over 300 references. All the diagrams and equations are very clear. The pro duction of the book owes very much to the care and dedication of Lothar Dresen, who worked very closely with the publishers in Britain to ensure that its form is every bit as good as its content.

A M Ziolkowski

Edimbargh University, UK

\section{Inventory of world topographic mapping, Volume 3, Eastern Europe, Asia, Oceania and Antarctica}

\section{Rolf Bohme \\ redited for the English language by Roger Anson)}

\section{Elsevier Applied Science Publishers, 1993, 447 pp.}

The index maps show at a glance the status of topographic mapping in 96 countries: the list starts with Albania and ends with a general map for Antarctica, introducing data on 15 separate Antarctic territories. In addition to the index sheets, the 'map extracts', small sample black-and-white squares, give the searcher some idea of the style, and kind of information available on particular map series.

As the President of the International Cartographic Association explains in the foreword, this is the third volume of the world inventory, the first part of which appeared in 1989; il marks the completion of a 'mammoth undertaking' under the auspices of the ICA. It can be appreciated that this was no easy task as far as the former territories of the Soviet Union were con- 
cerned: more recent. and as yet intractable difficulties have beset Yugoslavia, leading to fragmentation and renaming of political units. Also in the Asian countries the linguistic diversity and the variety of national approaches to the production of lopographic maps has meant that diverse styles of index map and different approaches to the transliteration of names in the various alphabetic schemes have challenged coher ence of presentation. Such a compilation requires time-consuming and diplomatic effort: it is no reflection, therefore, on the compilation, that the governments of Turkey, Saudi Arabia and Malaysia telt unable to make full contributions; however. it is satisfying to note that North Korea, also Laos and Vietnam, did provide some information.

For those inventory users requiring more detailed information on availability of topographic maps, current and future national policy, the national contact addresses will be particularly useful: these are given under the first subheading (National Mapping Organisation) in each national (or territorial) section. In every case this is succeeded by a brief history of topographic mapping in the country under con sideration, followed by notes on geodetic data for the maps which have been constructed, details of map scales and map series available, and a bibliography. The term 'bibliography' implies that the list is comprehensive, hut this may be difficult to contirm for many territories. The final sections deal with Antarctica. which has required a different treatment in that a seetion of "General Remarks", followed by what is clearly a short 'select' bibliography, serves to introduce the reader to data arranged under the various sectors: Argentina. Australia. Belgium, Chile, China. France. Germany. Japan. New Zealand,
Norway, Poland. South Africa, UK, USA and the former USSR.

Considering the polyglot nature of the contributions, the editing appears to have been meticulous: spelling errors, whether of Polish. Hebrew or Korean, remain unrecorded. The main problem has been the reproduction of some of the index maps and other material provided by the contributing countries: clearly without expensive and time-consuming redrafting this aspect of the compilation would be difficult to improve.

For example, a hand lens is required to home in on the details of a particular map in the index for Hokkaido (northern Japan). Iran or parts of Indonesia.

Former Czechoslavakia appears as the 'Crech and Slovalk Republic', i.e. still as one unit for the purposes of indexing. Estonia. I alvia and Lithuania are treated separately, whereas the other territories of the former USSR, such as Armenia and Kazakhstan, are subsumed under CIS (Commonwealth of Independent States): the map of index sheets for the CIS, produced in 1991 , is quite inadequate for such a large area-it is hoped that future editions will be able to present more detailed index maps for countries like Georgia and Uzbckistan. Whereas there are separate entries for Belarus and the Ukraine, an index map is available for the former, but not for the latter. It is understood that Bosnia \& Heryegovina, Croatia and Slovenia are given sepalrate entries, but referred to the former Yugoslavia; Serbia is not indexed in the contents, but Macedonia is keyed 10 'Yugoslavia' without a separate entry. Sadly. time must elapse before these anomalies can be sorted out in terms of spheres of national responsibility.

In the Middle East there is some inconsistency in dealing with the Arabic language, transliterated or otherwise, arising from dilferences in policy among the various countries. It helps the western reader to see that for Saludi Arabia and Bahrain the geographic names of the map sheets on the index are given in Arabic with Roman transliterations: no index map is presented for Iray, but those for Iran, Jordan. Syria and the United Arab Emirates are only in Arabic script, whereas the sheet names for Lebanon and Yemen appear only in roman. For Israel the scripts are both roman and Hebrew.

Blsewhere the index maps for Belarus and Bulgaria are entirely in Cyrillic seript. the index for Thailand is in the national script (although four sheets have been selected for highlighting in roman!) and the Japanese sheet names are given in the Kanji-Hiraganal system.

Picking nits: in the Pacific, Vanuatu is spelt incorrectly on the page headers as Vitmuatit. Also, why is the index map for this former Anglo-French Condominium entirely in French?

Notwithstanding these observations. and given the nature of the material, the edjtorial input for this publication deserves high commendation.

In the foreword the president of ICA emphasises the importance of improvine the status of world topographic mapping. The progress of research and development projects, resource analysis, environmental assessinents and leisure activities can be scriously frustrated if adequate topographic maps are not available. It is to be hoped that the completion of this third volume of the inventory will provide those who thirst for geographical information with a useful key, and that it will serve to enhance awareness of what needs still to be done, and where and how the priorities have to be drawn up.

B D Hackman

Rhos-on-Se'd, Chuvd, UK

BRITISH GEOL OGICAL SURVEY

\section{Analysed standards}

The following chemically analysed reference materials are available in powdered form: they are supplied with a certificate of analysis bearing statistically evaluated results from interlaboratory analyses of replicate samples. Both major and trace elements are included: the selection of elements varies according to the material analysed.

$\begin{array}{ll}\text { Sample No. } \\ 21 & \text { Nickel ore (norite) } \\ 22 & \text { Nickel ore (sepentinite) } \\ 23 & \text { Nickel ore (laterite) } \\ 24 & \text { Cobalt ore } \\ 26 & \text { Tin-tungsten ore } \\ 27 & \text { Molybdenum-lungsten ore } \\ 29 & \text { Pyrolusite } \\ 30 & \text { Chromite } \\ 31 & \text { Ilmenite } \\ 32 & \text { Rutile } \\ 33 & \text { Columbite } \\ 34 & \text { Tantalite }\end{array}$

Sample No.

35 Zircon

36 Monazite

37 Uranium ore

38 Baryte

39 Fluorite

40) Bastnäsite. millfeed ore

41 Bastnäsite, unleached concentrate

42 Lead concentrate

4.3 Zinc concentrate

44 Copper matte

100 Copper concentrate (in preparation)

For details of elemental composition, analysis results and purchase prices, please contact Mr I K Page, BGS Keyworth. 